\title{
O debate teórico em segurança internacional Mudanças frente ao terrorismo?
}

Gunther Rudzit*

\section{Introdução}

O tema de segurança internacional voltou a ser destaque tanto na mídia, quanto nos trabalhos acadêmicos. É senso comum que durante os anos da Guerra Fria esse enfoque foi central para as Relações Internacionais (RI), mas, com o desaparecimento desse conflito no final da década de 1980 e início da década de 1990, o enfoque desse campo de pesquisa mudou para a economia. Os ataques terroristas de 11 de setembro de 2001 mudaram novamente as percepções, e não se pode restringir essa nova realidade somente aos Estados Unidos.

O fim da Guerra Fria deu novo ímpeto à visão, defendida por alguns há muito tempo, de que interesses e desafios econômicos são mais importantes na condução do Estado do que os ligados à área militar. Nas palavras de Samuel Huntington no começo da década de 1990, no ambiente emergente "as capacidades militares provavelmente serão menos importantes do que elas

* Doutor em Ciência Política pela USP; Mestre em National Security pela Georgetown University e em Geografia pela USP; ex-Assessor do Ministro da Defesa (2001-2002); coordenador do curso de Relações Internacionais da Faap. E-mail: grudzit@yahoo.com

\begin{tabular}{|l|l|l|l|l|l|}
\hline Civitas & Porto Alegre & v. 5 & n. 2 & jul.-dez. 2005 & p. 297-323 \\
\hline
\end{tabular}


têm sido no passado. Medidas econômicas serão centrais..." (Huntington, 1991, p. 8). Tanto era assim que no Livro Branco de Defesa da Austrália, lançado em 2000, afirmava-se que "o recurso à força continuará a ser restringido por muitos aspectos do sistema internacional, e conflitos armados entre Estados deverão ser menos comuns do que em anos anteriores, mas sempre haverá o risco de que as circunstâncias possam mudar, e que essas restrições não sejam mais efetivas" (Governo Australiano, 2000, p. 7). Outras percepções também ganharam força.

Nota-se, contudo, que as circunstâncias mudaram, e o uso da força nas relações internacionais voltou a ser considerado não como possível, mas como de fato empregado, como se pôde observar no Afeganistão em 2002 e, principalmente, no Iraque em 2003. Correlato a esta idéia está o comentário do embaixador Rubens Ricúpero na orelha do livro lançado pelo professor Oliveiros Ferreira (2001), ao afirmar que o atual momento histórico está marcado por três características: a volta do predomínio do político sobre o econômico; a volta do poder de Estado sobre mercados; e, terceiro, os realinhamentos em curso que obedecem não à lógica dos mercados, mas à lógica do que Oliveiros Ferreira denomina de Grande Estratégia.

Por isso, a importância da compreensão sobre o uso da força em relações internacionais voltou a ter papel central. Essa aplicação do instrumento militar não está dissociada de outras políticas, tendo em vista que uma política de defesa de um Estado, em qualquer país do globo, pode ser explicada como decidida e executada dentro de uma estrutura composta por dois processos políticos, um externo e outro interno. O primeiro processo tem uma característica interestatal, e abarca a barganha e a negociação entre as nações por vantagens, nas quais a força ou a ameaça do seu uso é a medida básica de troca. $\mathrm{O}$ segundo processo é intra-estatal, o que significa o envolvimento das instituições que têm papel na definição das políticas de segurança nacional e de defesa e todos os aspectos da política interna de um Estado (Kolodziej e Harhavy, 1982, p. 15). Mas o que vem a ser segurança?

Pode-se dizer, grosso modo, que o debate teórico em Relações Internacionais está concentrado em dois campos. De um lado encontra-se o tradicional Realismo (ou também chamado de Racionalismo), e do outro o Idealismo (teoricamente chamado de Construtivismo). O campo da Segurança, ou Defesa, também seguiria esse mesmo debate sendo que ele começa pela conceituação do termo Segurança e da definição de sua abrangência. Novamente, 
Realistas e Construtivistas têm visões diferentes, dentre outras, sobre o foco que se deve observar quando se estiver abordando a segurança de um país. Essa questão é muito importante, pois muitas análises sobre segurança internacional são feitas sem uma base teórica adequada.

\section{O debate teórico em segurança}

Tradicionalmente, a maior parte da literatura nessa área é baseada nos conceitos de poder e paz. Aqueles a favor de uma abordagem baseada em poder derivam suas análises da escola realista de relações internacionais, a qual tem eminentes expoentes em E. H. Carr (1946), Hans Morgenthau (1973) e Kenneth Waltz (1979). Já os que favorecem a abordagem pela paz são mais associados à escola idealista, que tem o foco de análise primordialmente concentrado na segurança do sistema internacional, tentando conciliar essa perspectiva com a de segurança nacional. Na perspectiva idealista, ao se reduzir as ameaças externas ao Estado, reduzem-se as ameaças ao sistema internacional como um todo. Um dos expoentes desse pensamento é Martin Wight, que argüiu: “se há uma sociedade internacional, então há um certo tipo de ordem a ser mantida, ou mesmo desenvolvida". Não é uma falácia falar sobre um interesse coletivo, assim, segurança adquire um sentido mais amplo: ela pode ser usufruída ou perseguida em comum. Com o mundo mergulhado na bipolaridade da Guerra Fria, muitos acadêmicos tiveram que reforçar a perspectiva de que vários segmentos do sistema internacional estavam interligados a tal ponto que a segurança e bem-estar de cada um dependiam do outro, como pode ser percebido nas obras de Leonard Beaton (1972).

Os idealistas sustentam que seu conceito os permite ver não somente o problema em termos holísticos, em oposição à fragmentada visão dos realistas, mas também que eles focam suas atenções diretamente na essência do problema da guerra. E como a guerra é a maior ameaça proveniente do problema de segurança nacional, a solução para tal eliminaria em grande parte este problema da agenda internacional.

Portanto, os realistas tendem a ver a segurança como um derivativo do poder: um ator com suficiente poder que atinja uma posição dominante adquiriria como resultado a sua segurança. Já os idealistas tendem a ver a segurança como a conseqüência da $p a z$. Uma $p a z$ duradoura proveria segurança para todos. 
A principal evidência do não desenvolvimento do termo segurança como um conceito no campo das relações internacionais pode ser percebido pelo seu uso na literatura da área. O termo, muito usado tanto nesta como em outras disciplinas ou ainda por quem trabalha nos governos, tende a ser aceito como o conceito organizador da reflexão. Existe um grande número de trabalhos em que se estudam os problemas e tópicos de segurança nacional contemporâneos, no qual a segurança é o foco normativo central, sendo que a maior parte destes é proveniente da subárea de Estudos Estratégicos. As políticas externas, militares e econômicas dos Estados, a interseção das mesmas em áreas de mudança ou de disputa e a estrutura geral das relações que elas criam são todas analisadas como intenções a fim de se atingir a segurança nacional e/ou internacional.

Assim, apenas após a década de 1970, com o aparecimento das preocupações econômicas e ambientais, é que o conceito de segurança passou a ser tratado em outros termos e não somente como os interesses políticos de determinados atores. Mesmo assim, ao fim da década de 1980, a discussão ainda tinha uma grande ênfase militar.

Ao se pesquisar por um conceito comum na literatura sobre segurança, pouco será encontrado anterior a 1980. Após a Primeira Grande Guerra, deu-se um entusiasmo pela segurança coletiva, mas o fracasso da Liga das Nações e, posteriormente, das Nações Unidas em lidar com o assunto truncou os interesses nesta abordagem (cf. Pick, 1974; Stromberg, 1963; Naidu, 1974; Buzan, 1987, p. 265-67) O que pode ter sido um grande avanço foi a idéia de John Herz de "dilema da segurança" (security dilemma) no início dos anos cinqüenta (Hertz, 1950, 1951, 1959). Ou seja, adotava uma concepção estrutural na qual os Estados têm que obter por sua própria conta os meios necessários para a sua segurança, sem depender de ninguém (o que o autor chama de auto-ajuda). Entretanto, esta busca tende, não obstante, a seguir a intenção de somente se defender e, assim, a aumentar a insegurança dos outros, pois cada governo pode interpretar essas medidas tomadas pelos demais como potenciais ameaças, e procurará aumentar os seus próprios meios de defesa, daí o dilema da segurança.

Apesar da idéia do dilema da segurança ter sido amplamente reconhecida, o ambiente da Guerra Fria restringiu as percepções das pessoas quanto à dinâmica da ação-reação de potências rivais. Somente no final da década de 1970, com o trabalho de Robert Jervis, é que se inicia a tentativa de se retrabalhar o 
conceito, contudo, transferindo-se o foco da pesquisa para os elementos de "não-intenção" e interdependência das relações de segurança (Jervis, 1976, 1978, 1982). Entretanto, provavelmente, o conceito mais conhecido em segurança é apresentado no artigo de Arnold Wolfers (1962, cap. 10), no qual a ênfase em segurança nacional certamente reflete a orientação predominante na literatura empírica, sendo este trabalho considerado a introdução às complexidades multidimensionais do conceito. A caracterização que Wolfers dá à segurança como um "símbolo ambíguo" - em um ponto ele chega a argumentar que ela pode até mesmo não ter nenhum significado preciso - parece haver desencorajado-o em se interessar no desenvolvimento mais profundo desse conceito como o principal foco para se entender as relações internacionais.

Fora esses trabalhos, que podem ser considerados os mais aprofundados, podem-se encontrar alguns com discussões conceituais sobre segurança que são anteriores ao relativo rápido crescimento que se deu no início dos anos oitenta. Hedley Bull (1961), Bernard Brodie (1973), Frank Trager e Frank Simone (1973) fizeram pequenas mas muito úteis contribuições, sobre a dificuldade de aplicação do conceito. Hugh MacDonald tentou lidar com a ambigüidade do conceito, mas acabou derrotado por suas próprias análises e terminou afirmando ser "inadequado" o conceito (1981). Robert Jervis, após discutir a lógica anárquica do sistema internacional e o uso da força (1973), desenvolve a interessante idéia de "regimes de segurança", os quais retiram a atenção da análise do Estado para o nível do sistema (1976). Já Gert Krell (1979) tentou uma crítica ampla ao uso excessivo de conceitos militares dentro de uma perspectiva de pesquisa para a paz. Pode-se ainda encontrar discussões genéricas sobre o conceito no contexto da política externa americana. Por fim, a grande e bem difundida literatura em Estudos Estratégicos também contém comentários relevantes para o uso do termo segurança enquanto conceito relevante para as questões de Relações Internacionais (Buzan, 1987). Assim, a preponderância da correlação entre o conceito e a segurança nacional deu um tom militarizado à interpretação do que vem a ser propriamente a segurança.

Uma visão uniforme, contudo, predominou, pois, tanto acadêmicos quanto formuladores de políticas dentro dos governos, trabalharam o conceito de segurança como em termos de poder de cada nação. Isto porque os acadêmicos que pesquisavam o conceito estavam na maior parte apegados a uma visão de poder. Já os formuladores de políticas eram, e são, exigidos pelas suas posições, e pela natureza de seus poderes e responsabilidades, a ter uma visão predominan- 
temente nacional. E, como não há quase nenhum formulador de políticas que seja independente e acima do nível Estatal, com exceção de algumas instituições internacionais, a visão predominante do conceito de segurança está ligado ao conceito de Segurança Nacional.

\section{As relações entre estado e segurança: panorama geral dos estudos}

A Segurança Nacional somente pode ser entendida como um problema político quando se tem uma idéia razoavelmente clara sobre a natureza de uma ameaça, e as vulnerabilidades do objeto ao qual as ameaças são dirigidas. Esta distinção entre ameaças e vulnerabilidades aponta para a importante divisão dentro de uma política de segurança nacional, pois os Estados podem procurar reduzir as suas inseguranças através da diminuição de suas vulnerabilidades, ou enfraquecendo as fontes de ameaças (Art, 1973). Em outras palavras, uma política de defesa nacional tanto pode ter seu foco para dentro das fronteiras do país, a fim de reduzir sua vulnerabilidade por si mesmo, quanto para fora do Estado, procurando enfraquecer as ameaças externas indo diretamente às suas causas, por meio de negociações ou ataques armados diretos. Mas quais são as ameaças ou assuntos específicos da segurança (security issues)?

Atualmente há duas grandes correntes em estudos estratégicos que defendem perspectivas opostas quanto aos tópicos que devem ser considerados de Segurança Nacional: a tradicional ou "estreita", e a nova ou "abrangente". $\mathrm{O}$ debate entre as duas posições cresceu pelo descontentamento com o estreitamento que o campo de estudos estratégicos sofreu pela obsessão dos pesquisadores pelos aspectos militares em geral da Guerra Fria, principalmente o nuclear. Este sentimento foi estimulado pelo aparecimento das agendas econômica e ecológica no cenário internacional durante as décadas de 1970 e 1980, e mais tarde pelo aumento das preocupações de identidades nacionais e o surgimento e aumento dos crimes transnacionais na década de 1990. Contudo, esse movimento produziu uma "contra-reação", ou seja, um estreitamento dos estudos estratégicos centrados em torno dos temas de ameaças e uso da força. $\mathrm{O}$ argumento dos que defendem isso é de que a ampliação progressiva dos assuntos tratados poria em perigo a coerência intelectual dos estudos estratégicos, pois, ao se adicionar mais tópicos, acabaria por torná-lo vazio. 
Os que defendem explicitamente a ampliação são, dentre outros, Richard Ullman (1983); Egbert Jahn, Pierre Lemaitre e Ole Waever (1982); Joseph S. Nye e Sean M. Lynn-Jones (1988); Jessica Tychman Mathews (1989); Neville Brown (1989); Joseph S. Nye (1989); Neta C. Crawford (1991); Helga Haftendorn (1990), os quais enfatizam a urgência do estudo de novas fontes de ameaças não-militares. A defesa da posição tradicionalista foi ficando cada vez mais difícil com o arrefecimento e fim da Guerra Fria, contudo, até o final da mesma ainda se podiam encontrar argumentos a favor da restrição na área a qualquer coisa que seja concernente à prevenção da guerra nuclear das superpotências (Lebow, 1988, p. 508). Mas a principal tarefa da comunidade estratégica, ou seja, a análise da confrontação militar entre Leste e Oeste evaporou-se, e um período de desorientação se instalou. A função e, portanto, o status e fundação do edifício de estudos estratégicos que haviam sido construídos durante a Guerra Fria pareciam estar em risco; conseqüentemente, o foco militar da análise estratégica parecia estar extremamente vulnerável à pressão dos que queriam ampliar o enfoque. Um indicativo desse período foi a edição da revista Survival 31:6, de 1989, que foi totalmente voltada para os "aspectos não-militares da estratégia" (nonmilitary aspects of strategy).

Autores como Colin S. Gray (1994), lançaram-se na tentativa de reafirmar os argumentos convencionais da primazia dos aspectos militares. Em diversos graus os defensores deste ponto de vista aceitaram a necessidade de se incluírem mais causas não militares aos conflitos no sistema internacional. Mas, a maior parte dos tradicionalistas insiste no conflito militar como o elemento chave para se entender a segurança, e fizeram poucas tentativas de justificar a centralidade do Estado na análise de segurança, em grande parte, pela crescente presença de atores não estatais nesta nova conjuntura. Mas, alguns como Jahn, Lemaitre e Waever (1987) defendem o setor político como o foco principal de análise, enquanto Mohammed Ayoob (1995) defende o Estado como tal, diminuindo a importância do aspecto do conflito militar.

Apesar de pontos de vista diferentes, ambas as correntes definem o conceito de ameaça em termos de ser externo ou vindo de fora, isto é, de fora da unidade de análise mais aceita em relações internacionais: o Estado. Como Ayoob bem coloca (1995, p. 6), esta definição e o processo pelo qual se chegou a tanto podem ser entendidos pelo fato de que as duas correntes refletem a trajetória de trezentos anos de desenvolvimento histórico que pode ser traçado desde a Paz de Westphalia até o fim da Segunda Grande Guerra. 
A evolução do sistema de Estados europeus e sua interação com os processos de política interna de consolidação nacional levaram à legitimação do sistema e dos participantes individuais. Essas duas correntes - a interação entre os Estados soberanos e a grande identificação dos indivíduos com seus respectivos Estados - reforçou um ao outro, e com tal, criou-se a base para a tradição mais dominante na literatura de relações internacionais, na qual a segurança vira sinônimo da proteção contra ameaças externas aos interesses vitais e aos valores básicos de um Estado. Por fim, Ayoob acaba chamando essa corrente de "Conceito Ocidental de Segurança".

Entretanto, essa definição de segurança não pode ser aplicada na análise da situação de diversos países no mundo, primordialmente os que já foram chamados de Terceiro Mundo, ou hoje denominados de "Sul", em desenvolvimento ou até de Emergentes. Na sua busca por uma definição de um conceito que melhor se aplique à realidade dos países não desenvolvidos, Mohammed Ayoob desenvolve a idéia de que a dimensão internacional de segurança, a qual é inseparavelmente interligada com o processo de formação do Estado (State building), é o núcleo da variável que determina a problemática da segurança dos Estados não desenvolvidos (Ayoob, 1994, 1992). Ou seja, a definição de segurança por ele proposta tem como característica principal ser centrada no Estado, enfatizando a conotação política do termo, já que a maior empreitada na qual os países não desenvolvidos estão empenhados desde a descolonização é a formação do Estado (State building).

Isto porque, ao se tentar aplicar a definição ocidental de segurança na análise da situação de países não desenvolvidos, verificar-se-ão grandes problemas de conceituação, tendo em vista que as três maiores características deste conceito - orientação externa das ameaças, forte correlação da mesma com o sistema de segurança e ligação da mesma com a segurança dos dois principais blocos de alianças durante a Guerra Fria - é tão diminuta no terceiro mundo que o poder de explicação do conceito é enormemente diluído quando aplicado ao contexto dos países não desenvolvidos. Como exemplo, Ayoob usa o primeiro e fundamental atributo do conceito ocidental de segurança, a proveniência externa, já que a sensação de insegurança que estes Estados sofrem emana largamente de dentro das suas próprias fronteiras, ao invés de serem de fora delas. Apesar de essa situação não significar a não existência de ameaças externas, as ameaças internas têm maior visibilidade, pois são abundantes nos países não desenvolvidos, podendo-se argüir que tais 
conflitos freqüentemente se transformam em conflitos interestatais, devido ao fator de transbordamento dos mesmos para países vizinhos com os mesmos problemas internos.

Assim, as vulnerabilidades internas dos Estados não desenvolvidos são as principais causas para o elevado número de conflitos em diversas partes do globo abrangidas por esses países. As fissuras internas destes países têm ajudado na transformação desses conflitos internos em disputas interestatais, pois elas provêm as oportunidades e justificativas para Estados intervirem em disputas de seus vizinhos. Portanto, a principal causa dessa situação ocorre em decorrência das debilidades desses Estados.

Os baixos níveis de coesão social, legitimidade tanto do Estado quanto do seu regime, são as raízes das causas da situação de insegurança em que se encontram os países não desenvolvidos. Este baixo nível está relacionado à situação em que estes países se encontram, ou seja, ocorre por estarem nos primeiros estágios do processo de formação do Estado, e devido à falta de tempo que os mesmos tiveram para completar as diversas fases deste processo, ao contrário do que ocorreu na Europa Ocidental e América do Norte, como bem descreve Keith Jaggers:

Conceitualmente, a formação do Estado pode ser bem definida como a habilidade do Estado em acumular poder. A formação do Estado é um processo pelo qual um Estado não somente cresce em produtividade econômica e coerção governamental, mas, também, em poder político e institucional. Mais precisamente, em poder das elites do Estado em superar as forças do meio-ambiente, societária e política, as quais encontram-se no caminho dos seus objetivos políticos. Dados estes requerimentos, eu vejo o poder do Estado ter três faces distintas: (a) poder como capacidade nacional; (b) poder como capacidade política; e (c) poder como coerência institucional (Jaggers, 1992, p. 29).

As definições de Jaggers são semelhantes às de Edward Azar e Chung-in Moon de "security software" (1988). Segundo Azar e Chung, esse conceito é integrado por três componentes primários: legitimidade, integração e capacidade política. Portanto, pode-se dizer que o nível de segurança de um Estado está relacionado ao grau de desenvolvimento político alcançado por ele. Ao se tomar a definição de Charles Tilly sobre o processo de formação do Estado, que segue a formulação de Max Weber, pode-se complementar e estender o escopo da definição de Azar e Chung, pois para Tilly, o Estado é a principal fonte de violência organizada, argüindo que: 
[...] sob a liderança geral da violência organizada, os agentes do Estado caracteristicamente agem em quatro atividades distintas: 1) fazer a guerra: eliminando ou neutralizando seus rivais fora do território que eles têm clara e contínua prioridade como a autoridade da força; 2) formador do Estado: eliminando ou neutralizando os seus rivais dentro do seu território; 3 ) proteção: eliminando ou neutralizando os inimigos de seus clientes; 4) extração: adquirindo os meios para agir nas três primeiras atividades: fazer a guerra, formar o Estado e proteção (Tilly, 1987).

Tendo como base estas análises, pode-se concluir que o processo de formação do Estado pode ser descrito como o processo pelo qual o Estado não somente cresce economicamente e mantém a coerção governamental, mas também tem poderes políticos e institucionais, resultando no controle central do seu território e população, como o monopólio sobre os meios de violência dentro das fronteiras desse Estado, e a capacidade de permear significativamente a sociedade que é englobada por esse Estado.

Então, como definir a segurança de um Estado? O significado de segurança será tão diverso quanto as condições e situações de diferentes Estados a que este conceito é aplicado, assim como o processo de formação do Estado em países não desenvolvidos é diferente dos países do primeiro mundo. Os primeiros enfrentam problemas de segurança diferentes dos outros, que são a falta de legitimidade das suas fronteiras, instituições e regimes; coesão social inadequada e ausência de consenso da sociedade em assuntos sociais, econômicos e organização política (Ayoob, 1995, p. 28). Portanto, os países não desenvolvidos tendiam a se sentir mais ameaçados do que os de primeiro mundo, já que para eles as maiores ameaças partem muitas vezes de dentro do seu próprio território, sendo que para os desenvolvidos, normalmente, elas só vêem de fora de suas fronteiras.

Essa maior sensação de insegurança reforçou ainda mais a tendência de expansão do conceito de segurança no mundo pós Guerra Fria. Autores como Caroline Thomas e Jessica Mathews propuseram a ampliação desse conceito para passar a integrar a nova realidade do mundo. Thomas afirma que a segurança não se referiria somente à dimensão militar, mas uma maior, que englobasse toda a existência do Estado, como a procura por segurança interna através da construção do Estado (nation-building), por sistemas seguros de alimentação, saúde, monetário e de comércio (Thomas, 1987, p. 1). Mathews, por exemplo, procura apontar as mudanças climáticas e a devastação ambiental como as maiores fontes de insegurança nos anos noventa, e que serão os gran- 
des desafios do novo milênio (Mathews, 1991). Entretanto, a própria autora demonstra o conhecimento de que impacto da degradação ambiental em tópicos de segurança é muito difuso, e, portanto, é problemática a tentativa de se fazer esta correlação. Isto se dá tendo em vista que o declínio ambiental pode levar ocasionalmente a conflitos diretos, especialmente quando recursos hídricos escassos têm que ser divididos. Contudo, este impacto indireto na segurança das nações é sentido somente quando os reflexos da degradação ambiental afetam o desempenho econômico, e, portanto, agem na estabilidade política (Mathews, 1991, p. 366). Assim, fenômenos como pobreza e degradação ambiental deveriam ser analisados como ocorrências e variáveis que poderiam ser ligados ao campo da segurança, mas que na realidade não são parte constante dela.

Isso porque o conceito deve ser entendido, explicitamente, no sentido político. O conceito de segurança deve ser aplicado à segurança do Estado - em termos de território e suas instituições - e da segurança daqueles que representam a territorialidade e institucionalidade dele. Ou seja, uma situação de segurança/insegurança é definido em relação às vulnerabilidades, tanto interna quanto externa, que ameacem ou têm o potencial de derrubar ou enfraquecer as estruturas do Estado (territorial e institucional) e seu regime político (Ayoob, 1995, p. 9). De acordo com essa definição, quanto mais um Estado ou regime pender para o lado da invulnerabilidade no continuum vulnerabilidade/invulnerabilidade, mais seguro ele estará. Outros tipos de vulnerabilidades, tanto econômica ou ecológica, tornam-se componentes integrais da definição de segurança somente se eles se tornarem tão críticos que passem a ter dimensões políticas e ameacem as fronteiras do Estado, suas instituições, ou a sobrevivência do Sistema Político. Em outras palavras, dívida externa, devastação de florestas tropicais, ou até mesmo a fome não se tornam parte do cálculo de segurança a não ser que eles possam vir a ter resultados políticos que tanto afetem a sobrevivência das fronteiras do Estado, suas instituições ou enfraqueçam a capacidade do Estado em agir efetivamente nos campos das políticas interna ou externa.

Barry Buzan e seus colaboradores também definem segurança neste sentido (Buzan, 1998, p. 21). Para eles, segurança é sobrevivência, ou seja, somente se pode falar em segurança quando um assunto é apresentado como sendo uma ameaça real a algum objeto (tradicionalmente, mas não necessariamente o Estado, incorporando o governo, o território e sociedade). E utilizando-se de 
um conceito defendido por Waever afirmam que a especial natureza da ameaça justifica o uso de medidas extraordinárias a fim de lidar com ela. Por essa razão, a invocação da segurança tem sido a chave para a legitimização do uso da força, pois ela tem servido como a forma do Estado mobilizar ou invocar poderes especiais a fim de lidar com uma ameaça existente, real ou não, como observamos em relação às armas de destruição em massa (ADMs) de Saddam.

Buzan ainda faz uma profunda e interessante análise de como esse processo se dá, ao qual ele denomina de securitização. Para ele, segurança é o movimento que leva a política para além das regras do jogo estabelecidas e enquadra o assunto tanto como um tipo especial de política, como um conjunto de ações que se executam acima dela. Portanto, securitização pode ser entendida como uma versão mais extremada da politização, pois, em teoria, qualquer assunto público pode ser posicionado no espectro que varia do não-politizado (significando que o Estado não lida com ele e de nenhum modo é tido como um tópico de debate público e de decisões), passando por politizado (significando que o tópico é parte de uma política pública requerendo uma decisão governamental e alocação de recursos), indo até o securitizado (significando que o tópico é apresentado como uma ameaça existente, requerendo medidas de emergência, o que justifica ações fora dos limites normais do processo político). Em princípio, dependendo das circunstâncias, o posicionamento de qualquer tópico está em aberto, podendo estar presente em qualquer parte do espectro, pois, como visto anteriormente, uma questão pode ser conectada com outra e se dizer que é uma questão de segurança do Estado.

Ainda segundo Buzan, na prática, o posicionamento varia substancialmente de um Estado para outro e, conseqüentemente, através do tempo. A fim de justificar essa percepção o autor mostra com exemplos bastante ilustrativos como isso se dá em alguns Estados que politizam a religião (Irã, Arábia Saudita, Burma), e em outros que não o fazem (França e Estados Unidos). Mostra como alguns securitizam a cultura (a antiga União Soviética e o Irã), enquanto outros não (Reino Unido e Países Baixos) ilustrando as diferenças de posicionamento. No que se refere a certos tópicos, notavelmente meio-ambiente, houve uma mudança dramática saindo da categoria do nãopolitizado, sem ser possível dizer se foi elevado para a categoria de politizado ou para securitizado. Buzan ainda coloca que a ligação de politização e securitização não implica necessariamente que tal questão tenha de passar pelo Estado, sendo possível que ambos possam ser feitos em outros fóruns. 
Portanto, um tópico se torna de segurança não necessariamente por causa da existência de uma ameaça real, mas porque ele é apresentado como uma ameaça. Assim, a exata definição e critérios de securitização são constituídos pela intersubjetividade estabelecida por uma ameaça existencial com uma suficiente ênfase de que pode ter efeitos políticos substanciais. Por essa razão, um discurso que apresenta alguma coisa como uma ameaça existencial a um referido objeto não o torna securitizado em algum tópico que seja. Buzan denomina isso como um "movimento de securitização", pois um tópico somente é securitizado se e quando a audiência o aceitar como tal. Por isso, o caso da securitização é uma negociação entre um agente-securitizador e a audiência - ou seja, dentro de uma unidade (Estado) - e que somente assim o agente-securitizador poderá conseguir a permissão para não levar em consideração as regras vigentes, ou então, mudá-las, pois caso contrário ele as seguiria.

Acrescenta ainda que é importante notar que o discurso de segurança não é definido pelo uso da palavra, pois o essencial é a designação de uma ameaça existente que requer uma ação emergencial ou medidas especiais, e que a aceitação disso por uma parte significativa da audiência. Em algumas circunstâncias a palavra segurança aparecerá sem essa lógica, e nem sempre sua apresentação será de forma dramática, pois implicitamente é assumido que quando se fala a respeito desse tópico (tipicamente, mas não necessariamente em assuntos de defesa), estará sendo falado sobre ameaças.

\section{Complexos de segurança}

Tendo visto que segurança é um fenômeno relacional, atualmente, considera-se que não se pode entender a segurança nacional de um determinado Estado sem entender o padrão internacional de segurança interdependente em que ele estiver envolvido. Esta lógica nos leva a uma perspectiva holística complicada, pois se a segurança de cada um está relacionada com a segurança de todos, então nada pode ser plenamente entendido sem se compreender a totalidade. Tal perspectiva poderia, no limite, impossibilitar o estudo da segurança de qualquer Estado.

Novamente vale lembrar que todos os Estados estão imersos em uma teia global de interdependência de segurança. Mas como a maior parte das amea- 
ças políticas, e principalmente militares, podem ser mais facilmente percebidas em curtas distâncias, a insegurança é mais freqüentemente associada com a proximidade geográfica entre os Estados. Assim, o contexto mais amplo, ou seja, o nível global, é útil para o estudo das grandes potências, além de se poder pensar sobre objetos referentes sistêmicos (meio ambiente global, economia mundial etc.). Entretanto, para o modo tradicional de análise de segurança (político-militar), a segurança global passa a ser insuficientemente integrada para fazer sentido à maior parte das unidades - a segurança de Israel e Indonésia podem estar deteriorando, enquanto que para a Argentina e África do Sul podem estar melhorando, sendo que para Suécia e Japão continuam inalteradas - sem que nenhuma destas situações seja afetada pelas outras. Portanto, a racionalidade por detrás da teoria clássica de segurança é que para a maior parte dos atores no nível unitário, a segurança políticamilitar encontra-se em algum "aglomerado" de segurança, ou em um subsistema, ou então, em uma região. Isto porque a maior parte dos Estados teme mais os seus vizinhos do que potências distantes, conseqüentemente, a interdependência de segurança através de todo o sistema não é uniforme.

Por si mesma, a idéia de subsistema - definida por Haas como "qualquer conjunto" do sistema internacional (Haas, 1970, p. 100) - é muito abrangente para poder oferecer qualquer forma de orientação de como uma região pode ser definida. Hass e Brecher tentaram elaborar estruturas com o intuito de subordinar subsistemas baseados em amplas noções do que constituiria uma região (Haas, 1974; Brecher, 1973). Russet (1977) também seguiu esta linha de pesquisa, mas a partir da perspectiva de integração, sem conseguir se aprofundar mais no tema. O trabalho mais antigo e interessante nesta área foi elaborado por Cantori e Spiegel (1978), no qual procuraram elaborar uma estrutura comparativa para o estudo de relações regionais internacionais. Dentre as propostas apresentadas, vale destacar a importância da proximidade geográfica para se estabelecer regiões, e o papel que desempenham "sistemas intrusivos" nas relações regionais. Entretanto, a proposta se mostrou complexa demais para se poder chegar ao entendimento do que seria uma região, principalmente por tentar abordar toda a agenda de relações internacionais, e por tentar estabelecer uma estrutura comparativa de políticas muito detalhada. Conseqüentemente, como Thompson (1973) constata, nenhuma destas propostas resultou em uma definição amplamente aceita, muito menos em uma teoria coerente sobre o tema. 
Após esses trabalhos iniciais, surgiram outros que mantiveram a linha de alguns dos escritos em estudos de segurança. São exemplos significativos Herz (1950), Wolfers (1962) ou Jervis (1976), que enfatizam dinâmicas relacionais como dilemas de segurança, equilíbrio de poder, corridas armamentistas e regimes de segurança, além de trabalhos mais recentes como Ayoob (1983/4, 1986, 1989), Buzan e Rizvi et al. (1986), Väyrnen (1984, 1986) e Waever, Lemaitre e Tromer (1989), que conseguiram evitar a maior parte das dificuldades dos primeiros autores de segurança regional, ao enfocarem as suas análises em termos de relações de segurança em regiões.

Mais recentemente, Buzan desenvolveu melhor a teoria da segurança regional (Buzan, 1991, p. 188). Ele define, para começar, e de acordo com os autores antecessores dele, que em termos de segurança, "região" significa que um subsistema distinto e significativo de relações de segurança existe entre um grupo de Estados, cujo destino está determinado pela proximidade geográfica em que se encontram. Buzan explica que essa idéia de que um sistema regional tem historicamente sido muito forte no estudo do equilíbrio de poder europeu. Isso decorre do fato de que a Europa foi, e ainda é, um sistema regional, em virtude tanto das relações de poder, como das alianças nas escaladas de conflitos que unem todos os Estados entre si. Mas, do fato de que os Estados europeus dominaram o sistema-mundo, nenhum outro sentido forte de subsistema de segurança foi desenvolvido dentro do pensamento ocidental de relações internacionais, apesar do grande processo de descolonização, o qual deveria ter causado a reemergência de subsistemas de segurança locais, os quais, no final, foram sobrepujados pela rivalidade global das duas superpotências de então, os Estados Unidos e a União Soviética.

Ainda segundo Buzan, a única idéia tradicional de subsistema com potencial para os propósitos de análise de segurança é a noção de equilíbrio de poder local ou regional. Contudo, o autor aponta que esta idéia nunca provou ser muito útil precisamente porque ela está confinada a uma única dimensão - poder - no qual a capacidade maior das grandes potências se sobrepõe e ofusca as capacidades locais. Apesar de reconhecer que o equilíbrio de poder regional existe e é um aspecto importante de um ambiente de segurança, Buzan aponta que ele pode ser facilmente distorcido pelos movimentos dos recursos de abrangência global das grandes potências. Em virtude dessa suscetibilidade às influências externas, a elaboração de análises sobre equilíbrio 
de poderes locais é menos confiável para a compreensão das relações de segurança existentes na periferia do sistema internacional, do que ocorre no centro do sistema (Buzan, 1991, p. 188-9).

Continuando em sua análise, Barry Buzan afirma que ao se definir segurança regional, o principal elemento que deve ser adicionado às relações de poder é o padrão de relações amistosas ou de inimizade entre Estados. Ao se referir às amistosas, ele entende que os relacionamentos variam desde uma genuína amizade até expectativas de proteção e apoio, enquanto que inimizade vai dos relacionamentos definidos por desconfiança ao medo. Separando estes dois pólos, há uma grande faixa de indiferença e/ou neutralidade, na qual as relações amistosas e de inimizade são muito fracas para ter importância, ou então misturadas de tal forma que não produzem nenhuma inclinação para uma ou outra. Buzan afirma que uma visão extrema da teoria de equilíbrio de poder veria estes padrões de amistosas/inimizade como um produto do equilíbrio de poder regional, com Estados mudando suas alianças de acordo com os ditames dos movimentos na distribuição de poder. Segundo ele, a dinâmica histórica de laços amistosos e inimizade é parcialmente relacionada ao equilíbrio de poder, e quando é relacionada, é muito mais apegada do que o relativo movimento fluido da distribuição de poder (Buzan, 1991, p. 18990). Para exemplificar seu ponto de vista, ele toma como modelos os relacionamentos entre gregos e turcos, poloneses e russos, coreanos e japoneses, a fim de demonstrar que a inimizade pode ser particularmente duradoura quando adquire uma característica histórica. Conseqüentemente, os dois padrões devem ser considerados como fatores distintos na problemática da segurança.

Portanto, para Buzan, os padrões de amistosas/inimizade surgem de uma variedade de tópicos que não poderiam ser preditos a partir de uma simples consideração de distribuição de poder. Estes padrões variam de coisas específicas como disputas de fronteiras, interesses com populações étnicas afins e alinhamentos ideológicos a ligações históricas existentes há muito tempo, tanto positivas quanto negativas, tais como árabes e judeus, americanos e ingleses e vietnamitas e chineses. Assim, ao se adicionar ao quadro a dimensão amistosidade/inimizade, para ele pode-se ter a clara sensação dos padrões de relacionamento e a característica de insegurança ao invés do ponto de vista bruto do equilíbrio de poder. Nessa base, subsistemas de segurança regionais podem ser vistos em termos de padrões de amistosidade e inimizade que são substancialmente confinados dentro de uma área geográfica em particular. 
Buzan usa o termo complexo de segurança (security complex) para rotular as formações resultantes de tal processo. E ele define um complexo de segurança como um grupo de Estados cujas principais preocupações de segurança estão unidas de tal maneira que a segurança nacional de cada um não pode realisticamente ser considerada separada das outras (Buzan, 1991, p. 190). ${ }^{1}$ Barry Buzan diz que a denominação complexo de segurança tem a vantagem de indicar tanto a característica do atributo que define o grupo (segurança), quanto a noção da intensidade da interdependência que distingue qualquer grupo em particular dos seus vizinhos. E conclui, dizendo que complexos de segurança enfatizam a interdependência tanto de rivais como de interesses compartilhados.

Mais adiante, Buzan afirma que a tarefa de identificar um complexo de segurança envolve avaliações sobre a força da interdependência em segurança entre diferentes países. Para ele, em alguns países estas serão muito fortes, como entre Índia e Paquistão; em outros relativamente fracos, como entre Indonésia e Austrália; em alguns lugares a interdependência será positiva, como a mutuamente apoiada neutralidade de Suécia e Finlândia; em outros, negativa, como na rivalidade triangular entre Irã, Iraque e Arábia Saudita (Buzan, 1991, p. 192-3). ${ }^{2}$ Normalmente as interdependências surgem de relacionamentos locais, mas quando grandes potências são envolvidas, um grupo inteiro de Estados pode se unir por uma ameaça comum, tendo como maior exemplo os países da Europa Ocidental durante a Guerra Fria. Já em outros lugares a interdependência pode ser muito baixa, sendo que normalmente isto ocorre nas fronteiras entre duas áreas de maior interação, como, por exemplo, o caso de Burma/Miamar, que segundo Buzan é onde as dinâmicas de segurança do Sul e do Sudeste asiáticos se encontram.

1 Buzan (1991, p. 100-1) comenta em suas notas que ele acha original a idéia de complexos de segurança, apesar de se poder encontrar vestígios (shadows) dela em trabalhos anteriores sobre equilíbrio de poder e subsistemas. Michael Haas parece se mover em direção a esta idéia com sua noção de "subsistema-estratégico-militar" (military-strategic-subsistem), mas Buzan afirma que não acha que essa noção não foi desenvolvida por linhas similares às suas.

2 Cabe notar aqui que o exemplo dado entre Indonésia e Austrália está no contexto da época em que o texto foi escrito, pois atualmente, após a independência de Timor Leste, onde a atuação australiana foi de liderança no processo, indica que essa análise deveria ser refeita, demonstrando a possível mutação de um complexo de segurança. Portanto, fica claro a possibilidade de mudança de foco das relações sem ameaçar a existência do complexo de segurança. 
Assim, pode-se dizer que um complexo de segurança existe onde uma série de relações de segurança se destaca do "pano de fundo" global, em virtude de sua forte característica introspectiva e relativa fraqueza de interação de segurança "para fora" (Buzan, 1991, p. 193-4). Portanto, o fator principal para se definir um complexo de segurança normalmente é o alto nível de ameaça/medo que é mutuamente percebido entre dois ou mais grandes Estados, e a não ser que eles sejam potências de nível global, estes Estados habitualmente são vizinhos próximos. Um dos melhores indicadores continua sendo as guerras travadas anteriormente.

Como anteriormente dito, em virtude do fato dos complexos de segurança serem, em parte, entidades geográficas, normalmente eles incluem outros Estados menores. Tendo em vista o seu relativamente pequeno poder em comparação aos seus vizinhos, estes Estados podem ter pouco impacto na estrutura do complexo, sendo que sua própria segurança estará intimamente ligada ao padrão dos Estados maiores, mas somente podendo ser uma fonte de ameaça a esses pelo impacto de seu alinhamento com outros grandes vizinhos. Alguns deles podem ainda ter o papel de Estado "tampão" dentro da dinâmica local (Buzan, 1991, p. 195-6).

Buzan ainda levanta uma questão importante, quando pergunta se tanto laços culturais como raciais poderiam ser um fator para a identificação de complexos de segurança. Ele sustenta que parece não ser provável que características comuns culturais ou raciais de um grupo de Estados pode levá-los a prestar mais atenção uns aos outros, ou então a legitimar intervenções mútuas nos assuntos de segurança uns dos outros. Contudo, ele diz que se pode encontrar evidências de que culturas, tais como a árabe e a latino-americana, provavelmente facilitam e legitimam a interdependência de segurança em um grande grupo de Estados (Buzan, 1991, p. 196-7). ${ }^{3}$ Porém, Buzan conclui, que ao se definir a forma e estrutura de complexos de segurança, estas duas variáveis são padrões secundários, e não os primordiais.

Após discutir os parâmetros que servem de delimitação para os complexos de segurança, analisa ainda o que pode ser chamado de "história da segu-

3 O autor diz que baseia sua argumentação em uma palestra proferida por K. Subrahmanyam, que foi realizada no St. Antony's College, Oxford, em outubro de 1984, sobre a segurança do sul asiático, o qual este chama de "área civilizacional". 
rança regional". Com isso, procura identificar quais seriam os complexos de segurança, não só durante a história da civilização humana, mas também quais seriam eles atualmente nos países do Terceiro Mundo, tendo em vista que os complexos restantes já são bem estudados sob o aspecto do equilíbrio de poder das grandes potências, antes, durante e depois da Guerra Fria (Buzan, 1991, p. 202-6). Principalmente a região européia. Por isso, define que haveria cinco complexos de segurança no mundo não-desenvolvido, o SulAmericano, o Oriente Médio, o Sul Africano, Sul Asiático e do Sudeste Asiático.

Nota-se, contudo, que há um novo desafio para a análise de segurança internacional. Por isso, a análise de segurança que se quiser fazer de qualquer país, seja ela de que corrente for, deverá ter uma sólida base de dados sobre tal desafio, mesmo que o contexto internacional nunca possa ser esquecido, uma vez que ele tem influenciado o mundo inteiro devido às transformações de alcance global ocorridas durante os últimos sessenta anos.

\section{Segurança internacional e terrorismo}

É possível, ainda que complexo, entender a evolução teórica em segurança internacional compreendendo as mudanças que o mundo passou durante o século vinte e início deste novo milênio bem como as conseqüências dessas transformações para a humanidades. Na Primeira Guerra Mundial mais de oito milhões de soldados e mais de 6,6 milhões de civis foram mortos, tendo ainda mais de 21 milhões de soldados feridos (Dupuy, 1986, p. 990). Como resultado de Segunda Guerra Mundial há uma estimativa de 15 milhões de soldados e entre 26 e 34 milhões de civis mortos, e ao menos 25 milhões de soldados feridos (Dupuy, 1986, p. 1198). O pós-guerra também não foi muito diferente.

O período após 1945 é conhecido como “a longa paz” tendo em vista que as grandes potências não entraram em um confronto militar direto. Um dos aspectos mais perigosos da Guerra Fria foi a corrida nuclear entre Estados Unidos e União Soviética, quando acumularam um arsenal nuclear gigantesco de difícil compreensão para muitos (Gaddis, 1986). ${ }^{4}$ No auge desse en-

4 Gaddis (1986, p. 99-142); para maior análise veja: Muelle (1993). 
frentamento, na década de 1980, os arsenais das superpotências continham aproximadamente 24.000 bombas nucleares estratégicas e ao menos 23.000 armas nucleares táticas espalhadas pelo mundo (Brown, 1990). Muitas dessas armas têm potências mil ou duas mil vezes maior que as usadas em Hiroshima e Nagasaki.

O resultado dessa realidade levou autores a desenvolverem dois cenários. Uma guerra total entre Estados Unidos e União Soviética envolvendo dezenas de milhares de armas nucleares matando bilhões de pessoas. Isso obliteraria todas as grandes potências e terminaria com a civilização como nós a conhecemos. Esta é a visão dos otimistas. Os pessimistas acreditam que essa quantidade de explosões nucleares lançaria uma quantidade gigantesca de poeira e detritos na atmosfera, criando uma cobertura nuclear que impediria que os raios solares atingissem a superfície terrestre. Esse "inverno nuclear" mataria todos os seres humanos e provavelmente todos os animais e plantas. A possibilidade de autodestruição da humanidade havia se tornado uma realidade.

O fim da Guerra Fria teve um impacto positivo muito grande na segurança internacional. Com o colapso do império soviético na Europa oriental em 1989 e a desintegração da própria União Soviética em 1991, a ameaça de uma guerra em solo europeu ou uma guerra total nuclear praticamente desapareceu. Afora o benefício global dessa nova realidade, vários conflitos regionais que eram estimulados pela confrontação global tiveram um fim, como no Camboja, El Salvador, Nicarágua, Moçambique e Namíbia.

Mesmo que não tenha ocorrido uma confrontação entre as grandes potências, dezenas de outros conflitos tiveram lugar neste período. Apesar da incidência de conflitos interestatais ter diminuído nas décadas pós-1945, as guerras intra-estatais se tornaram prevalecentes no mundo. Somente 30 entre 164 guerras que aconteceram nesse período foram entre Estados, ou seja, somente $18 \%$. A grande maioria, ou seja, 126, ou 77\%, foram conflitos internos (Holsti, 1996, p. 21-5). Estima-se que o resultado dessa realidade foi a morte de aproximadamente 20 milhões de pessoas.

Nos primeiros doze anos do pós Guerra Fria (de 1990 a 2001), cinqüenta e sete grandes conflitos aconteceram em quarenta e cinco países. Na primeira metade desse período, o número de conflitos em qualquer ano esteve entre vinte e oito a trinta e três. Desde 1998 o número de conflitos se manteve ao 
redor de vinte e cinco por ano. No ano de 2003, conflitos estavam ocorrendo em lugares tão díspares como: Afeganistão, Argélia, Burma, Burundi, Colômbia, Costa do Marfim, Filipinas, Índia, Indonésia, Iraque, Israel, Paquistão, República Democrática do Congo, Rússia, Somália, Siri Lanka e Sudão, dentre outros (Eriksson, Sollenberg e Walesteen, 2002, p. 63-76). Portanto, quase todos os mais sangrentos conflitos nesse período foram intra-estatais ou intra-estatais com implicações regionais, sendo que somente quatro podem ser chamados de conflitos interestatais convencionais: Guerra do Golfo de 1991, a guerra fronteiriça entre Etiópia e Eritréia, entre 1998 e 2000, o conflito de Kargil, entre Índia e Paquistão, em 1999, e a Guerra do Iraque, em 2003. Portanto, o predomínio de conflitos intra-estatais é significativo.

Assim, o fim da Guerra Fria mudou fundamentalmente não só o ambiente de segurança internacional, mas também a sua análise como visto anteriormente. Em decorrência dessa nova realidade muitos autores passaram a incluir outros temas não militares nas suas análises de segurança. Entretanto, essa nova realidade não pode ser entendida como universal, já que a maioria dos países em desenvolvimento não se beneficiou dessas mudanças como os países mais desenvolvidos. A maior parte está imersa em uma teia de relacionamentos de segurança muito complexa, envolvendo conflitos internos e externos, além de uma série de novas ameaças como doenças, meio-ambiente, crime organizado, fatores econômicos, e o terrorismo, entre vários. Esse último aspecto é que tem chamado a atenção atualmente.

O terrorismo não é um fenômeno recente no cenário internacional, ele é quase tão antigo quanto a humanidade. No ano três a.C. já tivemos um exemplo claro do fenômeno quando um grupo de judeus assassinou aleatoriamente transeuntes em Jerusalém com o intuito de tentar promover uma revolta da população contra a ocupação romana. Contudo, somente com a Revolução Francesa é que surgiu o terrorismo com os contornos políticos que conhecemos hoje (Cronin, 2002-03, p. 34). A grande mudança nesta forma de ação, é que hoje, os terroristas buscam resultados grandiosos e chegam a morrer para atingir seus objetivos.

A forma de ação de grupos terroristas sofreu uma profunda modificação. Em 1999 um ex-Secretário de Defesa dos Estados Unidos e seu assessor, analisando as futuras ameaças ao país, defendiam que os novos atentados estavam em uma nova escala, denominando-os como "terrorismo catastrófi- 
co". Essa definição devera-se ao fato de que os grupos terroristas estavam buscando um resultado diferente da tomada de reféns, ou "simples explosões" e seqüestro de aviões, que desde a Olimpíada de Munique em 1972 poderiam ser chamados de "terrorismo comum". Eles tomaram como exemplo os atentados de Oklahoma City, World Trade Center (1994), as atividades da seita Aum Shinrikyo com gás sarin no metrô de Tóquio e o ataque ao quartel americano de Khobar Towers, na Arábia Saudita. Esses autores argumentam que essa mudança de escala em destruição buscaria solapar a sensação de segurança da população americana em sua crença de que os Estados Unidos eram um lugar seguro para se viver (Carter e Perry, 1999, 149-150). Assustadoramente, os dois estavam certos, e o mundo tomou ciência disso com os eventos do 11 de setembro de 2001 .

Contudo, o que mais chocou nos atentados contra os Estados Unidos foi a disposição dos seus perpetradores em perder a própria vida a fim de levar a cabo o seu ataque. Na verdade, não foi o primeiro atentado do gênero, pois os grupos palestinos praticaram vários atentados desse tipo em Israel, para pressionar o governo israelense a se retirar da Faixa de Gaza e Cisjordânia. O mesmo modelo de terrorismo foi realizado pelo grupo Tigres Tamil de Libertação de Eelam, para compelir o governo de Siri Lanka a aceitar a independência Tamil, e a própria Al Qaeda já assim havia agido para pressionar os Estados Unidos a se retirarem da Arábia Saudita.

Isso mostra que tais ataques não são novidades, apenas houve um aumento no seu número e localização, pois desde o atentado à embaixada americana em Beirute em abril de 1983, houve, ao menos, 188 ataques suicidas no mundo. A questão é que sua taxa subiu de 31, na década de 1980, para 104 na década de 1990 e, posteriormente, para 53 nos anos 2000-2001 (Pape, 2005, p. 232-249). Mais importante ainda foi o aumento do número de mortes nos atentados: subiu de 344, em 1991, para 6.693 em 1998. Em termos percentuais, por período, o aumento chega a ser espantoso: subiu significativamente de 102 mortes em 565 ataques em 1991, para 741 mortes em 274 ataques em 1998 (Cronin, 2002-03, p. 43). Por isso, pode-se afirmar que o terrorismo passou a existir em escala mundial com essa nova característica: é "suicida catastrófico".

$\mathrm{O}$ aumento do número de atentados e mortes de ataques terroristas em todo o mundo passou a ser um dos focos centrais de debate em segurança 
internacional. Uma das causas para essa centralidade no debate se deve ao fato de que o governo americano passou a focar as políticas externas e de defesa no combate ao terrorismo internacional. Contudo, no debate teórico não há muita diferença, pois o terrorismo se encaixa tanto nas análises a tradicional (estreita), como a nova (abrangente). Isto se deve ao fato de que o terrorismo é apenas mais uma ameaça, seja ele externo ou interno. Assim, as duas correntes identificam-no dentro das suas tradicionais formas de análise.

Ocorreu, entretanto, um grande impacto das políticas de segurança no mundo todo. Tendo em vista que células terroristas, ligadas ou não à $\mathrm{Al}$ Qaeda, estão atuando em diversos países desenvolvidos, isso fez com que os governos desses países passassem a dar maior atenção às ameaças vindas de dentro do seu próprio território, como no caso dos americanos que tiveram que criar uma agência de segurança com nível ministerial (Homeland Security Office) para fazer frente a essa nova ameaça. Por conseguinte, hoje, tanto os países desenvolvidos, quanto os em desenvolvimento, têm que levar em consideração ameaças vindas de dentro do seu próprio território, mesmo para aqueles que estão mais avançados no processo de construção do Estado.

\section{Referências}

ANGELL, Norman. The great illusion. New York: Putman's, 1913.

ART, Robert J.; JERVIS, Robert. International politics: anarchy, force, imperialism. Boston: Little and Brown, 1973.

ASHLEY, Richard K. The political economy of war and peace: the sino-sovietamerican triangle and the modern problematique. London: Pinter, 1980.

AYOOB, Mohammed. Security in the third world: the worm about turn? International Affairs, v. 60, n. 1, 1983-4.

. (Org.). Regional security in the third world: case studies from Southeast Asia and Middle East. London: Croom Helm, 1986.

- The Third World in the system of states: acute schizophrenia or growing pains? International Studies Quarterly, v. 33, v. 1, 1989. 1995.

. The Third World security predicament. Boulder: Lynne Reinner Publishers,

AZAR, Edward E.; MOON, Chung-in (Orgs.). National security in the third world: the management of internal and external threats. College Park: Center for International Development and conflict management, University of Maryland, 1988. 
BEATON, Leonard. The reform of power: a proposal for an international security system. London: Chatto and Windus, 1972.

BRECHER, Michael. International relations and asian studies: the subordinate state system of Southern Asia. World Politics, v. 15, n. 2, 1963.

BRODIE, Bernard. War and politics. London: Cassell, 1973.

BROWN, Michael. Recent and prospective developments in nuclear arsenals. In: SUR, Serge (Org). Nuclear deterrence: problems and perspectives in the 1990's.

BROWN, Neville. Climate, ecology, and international security. Survival, v. 31, n. 6, 1989.

BULL, Hedley. The control of the arms race. London: Weindenfeld e Nicolson, 1961.

BUTTERFIELD, Herbert; WIGTH, Martin (orgs.). Diplomatic investigations. London: Allen and Unwin, 1966.

BUZAN, Barry. Common security, non-provocative defense, and the future of Western Europe. Review of International Studies, v. 13, n. 4, p. 265-7, 1987.

- An introduction to strategic studies: military technology and international relations. London: Macmillan, 1987.

. People, states and fear. An agenda for international security studies in the post-cold war era. Boulder: Lynne Rienner Publishers, 1991.

; RIZVI, Gowher et al. South Asian insecurity and the great powers. London: Macmillian, 1986.

; WAEVER, Ole; WILDE, Jaap de. Security: a new framework for analysis. Boulder: Lynne Reinner Publishers, 1998.

CANTORI, Louis J.; SPIEGEL, Steven L. The international politics of regions: a comparative approach. Englewood Cliffs: Prentice Hall, 1970.

CARR, E. H. Vinte anos de crise: 1919-1939 - uma introdução ao estudo das relações internacionais. Brasília: UnB, IPRI; São Paulo: 2001.

CARTER, Ashton B.; PERRY, William J. Preventive defense. a new security strategy for America. Washington: Brookings Institution Press, 1999.

CREAWFORD, Neta C. Once and future security studies. Security Studies, v. 1, n. 2, 1991.

CRONIN, Audrey Kurth. Behind the curve: globalization and international terrorism. International Security, v. 27, n. 3, inverno 2002-03.

EVANS, Peter B.; RUESCHEMEYER, Dietrich; SKOCPOL, Theada (Orgs.). Bringing the state back in. New York: Cambridge University Press, 1985.

DUPUY, R. Ernest; DUPUY, Trevor N. The encyclopedia of military history from 3500 B.C. to the present, 2. ed., New York: Harper and Row, 1986. 
ERIKSSON, Mikael; SOLLENBERG, Margareta; WALLESTEEN, Peter. Patterns of major armed conflicts, 1990-2001. In: Stockholm International Peace Research Institute (SIPRI). SIPRI Yearbook 2002: armaments, disarmament, and international security. Oxford: Oxford University Press, 2002.

FERREIRA, Oliveiros S. Crise da política externa: autonomia ou subordinação? São Paulo: Renavan, 2001.

GADDIS, John Lewis. The long peace: elements of stability in the postwar international system. International Security, n. 10, primavera 1986.

GOVERNO AUSTRALIANO. Defense white paper. Defense 2000 - our future defense force. Canberra: Department of Defense, 2000.

GRAHAM, Norman (org.). Seeking security and development: the impact of military spending and arms transfers. Boulder: Lynne Rienner Publishers, 1994.

GRAY, Coli S. Villains, victims and sheriffs: strategic studies and security for an inter-war period. Hill: University of Hull Press, 1994.

HAFTENDORN, Helga. The security puzzle: theory-building and discipline-building in International Relations. International Studies Quarterly. v. 35, n. 1, 1990.

HAAS, Michael. International subsystems: stability and polarity. American Political Science Review, v. 64, n. 1, 1970.

_. International Conflict. Indianapolis: Bobbs-Merrill, 1974.

HERZ, John H. Idealist internationalism and the security dilemma. World Politics, n. 2, 1950 .

Press, 1951.

Political realism and political idealism. Chicago: University of Chicago

International politics in the atomic age. New York: Columbia University Press, 1959.

HÖLL, Otmar (Org.). Small states in Europe and dependence. Vienna: Austrian Institute for International Affairs, 1983.

HOLSTI, Kalevi J. The state, war, and the state of war. Cambridge: Cambridge University Press, 1996.

HUNTINGTON, Samuel P. America's changing strategic interests. Survival, London: International Institute for Strategic Studies, jan. feb. 1991.

JAGGERS, Keith. War and the three faces of power: war making and state making in Europe and the Americas. Comparative Political Studies, v. 25, n. 1, abr. 1992.

JAHN, Egbert; LEMAITRE, Pierre; WAEVER, Ole. Concepts of security: problems of research on non-military aspects. Copenhagen Papers, n. 1, Copenhagen: Center for Peace and Conflict Research, 1987. 
JERVIS, Robert. Perception and misperception in international politics. Princeton: Princeton University Press, 1976.

. Cooperation under the security dilemma. World Politics, v. 30, n. 2, 1978.

_. Security Regimes. International Organization, v. 36, n. 2, 1982.

JOB, Brian (Org.). The insecurity dilemma: national security of third world states. Boulder: Lynne Rienner Publishers, 1992.

KATZENSTEIN, Peter J. (Org.). The culture of national security: norms and identity in world politics. New York: Columbia University Press, 1996.

KLARE, Michael; THOMAS, Daniel (Orgs.). World security: trends and challenges at Century's end. New York: St. Martin's Press, 1991.

KOLODZIEJ, Edward A.; HARHAVY, Robert E. Security policies of Developing Countries. Lexington, Toronto: Lexington Books, 1982.

KRELL, Gert. The development of the concept of security. Arbeitspapier 3. Frankfurt: Peace Research Institute, 1979.

LEBOW, Richard N. Interdisciplinary research and the future of peace and security studies. Political Psychology, v. 9, n. 3, 1988.

LIPSCHUTZ, Ronnie D. (Org.), On security. New York: Columbia University Press, 1995.

MACDONALD, Hugh. The place of strategy and the idea of security. Millennium, v. 10, n. 3, 1981.

MATHEWS, Jessica Tychman. Redefining Security. Foreign Affairs, v. 68, n. 2, 1989.

MORGENTHAU, Hans. Politics among nations. New York: Knopf, 1973.

MUELLER, John. Retreat from Doomsday: the obsolescence of major war. New York: United Nations, 1993.

NAIDU, M. V. Collective security and the United Nations. Delhi: Macmillan, 1974.

NYE, Joseph S.; Lynn-Jones, Sean M. International security studies. International Security, v. 12, n. 4, 1988.

NYE, Joseph S. The contribution of strategic studies: future challenges. Adelphi $\mathrm{Pa}$ per n. 235. London: International Institute for Strategic Studies, 1989.

PAPE, Robert A. The strategic logic of suicide terrorism. In: ART, Robert J.; JERVIS, ROBERT, International Politics: enduring concepts and contemporary issues. New York: Pearson Education, 2005.

PICK, Otto; CRITCHLEY, Julian. Collective security. London: Macmillan, 1974. 
RUSSETT, Bruce. International relations and international system. Chicago: University of Chicago Press, 1967.

STROMBERG, Roland N. Collective security and American foreign policy. New York: Praeger, 1963.

THOMAS, Caroline. In search of security: The Third World in international relations. Boulder: Lynne Rienner Publishers, 1987.

THOMPSON, William R. The regional subsystem: a conceptual explication and a prepositional inventory. International Studies Quarterly, v. 17, n. 1, 1973.

TRAGER, F. N., KRONENBERG, P. S. (Orgs.) National security and American society. Lawrence: University Press of Kansas, 1973.

ULLMAN, Richard. Redefining security. International Security, v. 8, n. 1, 1983.

VÄYRYNEN, Raimo. Regional conflict formulations: an intractable problem of international relations. Journal of Peace Research, v. 21, n. 4, 1984.

. Collective violence in a discontinuous world: regional realities and global fallacies. International Social Sciences Journal, v. 38 n. 4, 1986.

WAEVER, Ole; LEMAITRE, Pierre; TROMER, Elzbieta. European polyphony: perspective beyond East-West confrontation. London: Macmillian, 1989.

WALLANDER, Celeste A. Mortal friends, best enemies: German-Russian cooperation after the Cold War. Ithaca: Cornell University Press, 1998.

WALTZ, Kenneth. Theory of International Politics. Reading: Addison-Wesley, 1979.

WIGHT, Martin, Western Values. In: BUTTERFIELD, Herbert; WIGHT, Martin (orgs.). Diplomatic Investigations. London: Allen and Unwin, 1966.

WOLF, Charles. Economic instruments, military instruments, and National Power. In: The Korean Journal of Defense Analysis, n. 2, (winter 1994).

WOLFERS, Arnold. National Security as an ambiguous symbol. Discord and Collaboration 7. Baltimore: Johns Hopkins University Press, 1962.

. Discord and collaboration: essays on international politics. Baltimore: Johns Hopkins University Press, 1962.

Recebido em 20 de março de 2005 e aprovado em 20 de julho de 2005 